\title{
Tailoring spin mixtures by ion-enhanced Maxwell magnetic coupling in color- tunable organic electroluminescent devices
}

\author{
Junwei $X u^{1,2}$, Yue Cui ${ }^{1,3}$, Gregory M. Smith ${ }^{1,2,9}$, Peiyun Li $i^{2,4}$, Chaochao Dun ${ }^{1,2}$, Linqi Shao ${ }^{1,5}$, Yang Guo ${ }^{1,6,7}$, \\ Hongzhi Wang ${ }^{6,7}$, Yonghua Chen ${ }^{8}$ and David L. Carroll ${ }^{1,2}$
}

\begin{abstract}
In this work, we show that the spin dynamics of excitons can be dramatically altered by Maxwell magnetic field coupling, together with an ion-enhanced, low-internal-splitting-energy organic semiconducting emitter. By employing a unique, alternating current (AC)-driven organic electroluminescent (OEL) device architecture that optimizes this magnetic field coupling, almost complete control over the singlet-to-triplet ratio (from fluorescent to phosphorescent emission in a single device) is realized. We attribute this spin population control to magnetically sensitive polaron-spin pair intersystem crossings (ISCs) that can be directly manipulated through external driving conditions. As an illustration of the utility of this approach to spin-tailoring, we demonstrate a simple hybrid (double-layer)

fluorescence-phosphorescence (F-P) device using a polyfluorene-based emitter with a strong external Zeeman effect and ion-induced long carrier diffusion. Remarkable control over de-excitation pathways is achieved by controlling the device-driving frequency, resulting in complete emission blue-red color tunability. Picosecond photoluminescence (PL) spectroscopy directly confirms that this color control derives from the magnetic manipulation of the singlet-totriplet ratios. These results may pave the way to far more exotic organic devices with magnetic-field-coupled organic systems that are poised to usher in an era of dynamic spintronics at room temperature.
\end{abstract}

\section{Introduction}

In today's current-driven organic electroluminescence (OEL) devices, of which organic lighting diodes are a subset, free charges are injected through metal contacts into an organic semiconductor, where they can recombine into electron-hole $(\mathrm{e}-\mathrm{h})$ pairs and decay to emit photons $^{1,2}$ (or they can be transported through the layer without interacting). Quantum statistics dictates that the fraction of spin pairs that are formed in the spin-triplet excited state is generally fixed at $75 \%$. The spin-singlet states make up the remaining $25 \%$ of the excited-state

Correspondence: David L. Carroll (carroldl@wfu.edu)

${ }^{1}$ Center for Nanotechnology and Molecular Materials, Wake Forest University, Winston-Salem, NC 27109, USA

2Department of Physics, Wake Forest University, Winston-Salem, NC 27106, USA

Full list of author information is available at the end of the article. population $^{3,4}$. This means that when re-combining injected spin-1/2 polaron-spin pairs for $E L$, three of every four possible spin combinations will be triplets (with nonradiative or infrared decay routes), and one of the four will be a singlet (fluorescent emission). This has prompted the use of triplet scavenging dyes that resonantly transfer the triplet energy to a metal complex (e.g., Pt, Os, Ir, Au, $\mathrm{Pd}$, or $\mathrm{Ru}$ ) with strong L-S coupling ${ }^{5-7}$, which allows phosphorescent emission and higher device efficiency.

The resonant transfer of energy is useful for lighting and display applications. However, owing to the lifetimes involved in triplet transfer or decay, the limits on the current flux and dye concentrations due to co-localization of triplet energy, and the subsequent quenching, among other considerations, resonant energy transfer does not address the issues that spin-triplets cause for highperformance light-emitting applications. These potential 
but unrealized applications include the electrically stimulated organic laser ${ }^{8}$, the photonic spin valve, organically based optical computing paradigms, and telecommunications. Without more complete spinpopulation control, it is unlikely that any of these technologies will be realized using the organic platform ${ }^{9}$.

Until recently, there did not seem to be any way to beat the statistics of this problem. However, in $2007^{10}$, a hint was provided experimentally in the negative magnetoresistance of an organic semiconductor device. The typical $75 \%: 25 \%$ ratio of triplets to singlets is not maintained when external, static magnetic fields are present. This has been attributed to a spin remixing in the polaron-spin pairs that is typically found in organic systems ${ }^{10-13}$. Simply, the external magnetic field can perturb the coherent relationship between electron and hole spin precessions ${ }^{14-16}$. Therefore, an enhanced singlet-related emission can be observed in a florescent semiconducting polymer that has a low internal splitting energy or a strong Zeeman effect. However, phosphorescent organic semiconductors do not exhibit the spin remixing property in the external magnetic field since the heavy metal atom can significantly raise the internal splitting energy of the organic compound ${ }^{13}$. Moreover, in magnetically coupled OEL devices, the redistribution of singlet and triplet $\mathrm{e}-\mathrm{h}$ pairs can give rise to a significant change in the electrical current in the semiconductor through dissociation ${ }^{17-21}$ and charge reaction ${ }^{22-25}$ (Figure S1). However, the key to utility is to extend this control over the spin populations.

By utilizing the magnetic field spin remixing phenomena, in our present work, a novel device architecture is optimized to self-couple the time-dependent Maxwell field into the ion-assisted emitter. With a suitable choice of emitters for this structure, a high color contrast in spinstate ratios for a single compact device structure can be achieved. Color-tunable pixels have a unique potential for use in ultra-high-resolution information displays ${ }^{26,27}$ since they allow for an optimal fill factor and impart further momentum toward realizing high-definition micro-displays. One of most common color-tuning strategies is to induce a voltage-dependent color shift via a spatial shift of the recombination zone or exciton redistribution within a multi-layered device ${ }^{28,29}$. However, this leads to inevitable brightness changes and quenching in the high fields, making the voltage-dependent color-tunable devices more difficult and expensive to commercialize. Another method seen in the literature is to stack two or three color-independent OEL segments into a tandem device $^{27,30}$. However, stacking tandem EL structures requires complicated multiple thin film deposition and designs of electrical power for multiple electrodes.

Here a color-change hybrid alternating current (AC)driven OEL device is driven with a high-frequency AC electric field. This yields a Maxwell AC magnetic field that is coupled to the organic emitter, namely, a $\mathrm{p}-\mathrm{n}$-emitting interface. The internal AC magnetic field allows the manipulation of the ratio between singlet and triplet $\mathrm{e}-\mathrm{h}$ pairs in an n-type fluorescent material by suppressing intersystem crossing (ISC) to generate diffusive secondary carriers. Then these ion-enhanced secondary carriers produce triplet-spin excitons in a proximal phosphorescent organic matrix. In the magnetically coupled fluorescence-phosphorescence (F-P) hybrid OEL device, we successfully shifted the CIE coordinates of the radiative output from $(0.23,0.34)$ to $(0.53,0.40)$ by manipulating the driving frequency from 50 to $60,000 \mathrm{~Hz}$ with no significant brightness change.

\section{Results}

Our device architecture (Fig. 1a) borrows from the "gated" AC-OEL structure that were introduced recently in the literature ${ }^{31}$. In this case, however, the gated structure is coupled to a bilayer organic emitter consisting of [poly(N-vinylcarbazole) (PVK):bis(2-methyldibenzo[f,h] quinoxaline) (acetylacetonate)iridium(III) (Ir(MDQ) $)_{2}$ (a$\mathrm{cac}))$ and poly[(9,9-bis(3'-((N,N-dimethyl)-N-ethylammonium)-propyl)-2,7-fluorene)-alt-2,7-(9,9-dioctylfluorene)] (PFN-Br)]. Surface morphology analyses of PVK:Ir(MDQ $)_{2}(\mathrm{acac})$ and PFN-Br emissive layers are performed via atomic force microscopy (AFM); the obtained images can be found in Figure S2. As in an earlier work ${ }^{32}$, the carrier gate layer was composed of [poly(3,4-ethylenedioxythiophene) polystyrene sulfonate (PEDOT:PSS) that was loaded with $\mathrm{ZnO}$ nanoparticles (NPs) $]$ and the electron-transporting layer was $\left[2,2^{\prime}, 2^{\prime \prime}-\right.$ (1,3,5-benzinetriyl)-tris(1-phenyl-1-H-benzimidazole)

(TPBi)]. The two conductive electrodes were indium tin oxide (ITO) and aluminum (Al). The chemical structures of the emitters, namely, PFN-Br and $\operatorname{Ir}(\mathrm{MDQ})_{2}(\mathrm{acac})$, are listed in Fig. 1b. With $365 \mathrm{~nm}$ ultraviolet (UV) excitation, PFN-Br and $\operatorname{Ir}(\mathrm{MDQ})_{2}(\mathrm{acac})$ show strong fluorescent and phosphorescent luminescence peaks at 474 and $585 \mathrm{~nm}$, respectively (as shown in Fig. 1c). The lifetimes of shortlived blue fluorescence and long-lived red phosphorescence are given in Fig. $1 \mathrm{~d}$ for $0.31 \mathrm{~ns}$ and $1.87 \mu \mathrm{s}$, respectively. With $\mathrm{ZnO}$ NPs ( $\sim 35 \mathrm{~nm}$ in diameter) gating the interface of ITO/PEDOT:PSS, injected charges can be efficiently manipulated under the forward and reverse biases of AC cycles $^{32-34}$. The AC-OEL devices are driven by a sinusoidal voltage with a wide frequency range from $50 \mathrm{~Hz}$, which causes the gate to allow bi-polar injection and the device to act like a diode, to $60,000 \mathrm{~Hz}$, at which most light is created by field-generated polarons/excitons with little diffusive transport in the active volume of the emitter. The operating mechanism of AC-OEL devices is described in detail in Supplemental Information.

$\mathrm{PFN}-\mathrm{Br}$ is a high-performance ionized electrontransporting polymer ${ }^{35,36}$ with an electron mobility of 

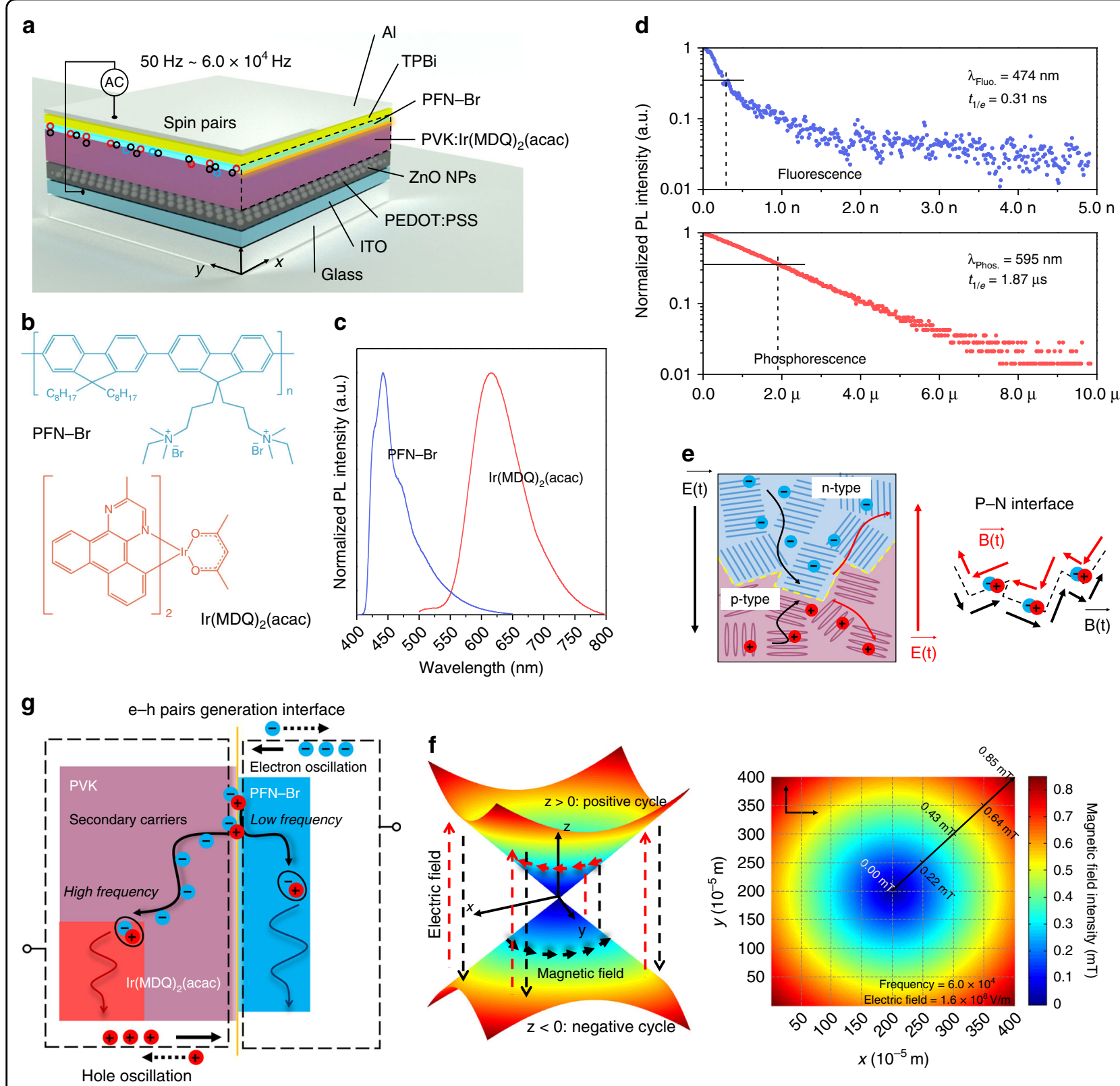

Fig. 1 Structural and electromagnetic characterization of color-tunable AC-OEL devices. a Compositional schematic diagram of devices with a fluorescence-phosphorescence (F-P) emission interface driven by an AC power source $(50-70,000 \mathrm{~Hz}$ ). Singlet spins (blue circle pairs) and triplet spins (red circle pairs) are formed at the PVK/PFN-Br interface (or F-P interface). $\mathbf{b}$ The chemical structures of PFN-Br and $\operatorname{Ir}(\mathrm{MDQ})_{2}(\mathrm{acac})$.

c Fluorescence of PFN-Br at $474 \mathrm{~nm}$ and phosphorescence of Ir(MDQ) 2 (acac) at $595 \mathrm{~nm}$. d Photoluminescence (PL) decay curves of PFN-Br fluorescent emission (top) and $\operatorname{Ir}(\mathrm{MDQ})_{2}(\mathrm{acac})$ phosphorescent emission (bottom). e Schematic diagram of dynamic field analysis at the $p-n$ magnetic interface. f Simulated results of magnetic and electric fields at the $p-n$ junction at $60,000 \mathrm{~Hz}$. The maximum self-generated magnetic field is $0.85 \mathrm{mT}$. In the positive and negative halves of the AC driving cycle, the directions of the vertex magnetic fields are clockwise $(z>0)$ and counterclockwise $(z<0)$, respectively. $\mathbf{g}$ Proposed working principle of the e-h pair generation interface. Radical triplet excitons are generated in $\operatorname{Ir}(\mathrm{MDQ})_{2}(\mathrm{acac})$ by secondary carriers for red phosphorescent emission at high frequency. At low frequency, radical singlet excitons decay in PFN-Br for blue fluorescent emission

$1.41 \times 10^{-7} \mathrm{~cm}^{2} / \mathrm{V} / \mathrm{s}$, and PVK is a typical p-type semiconductor with a hole mobility on the order of $1.0 \times 10^{-6}$ $\mathrm{cm}^{2} / \mathrm{V} / \mathrm{s}$. Thus electrons and holes are transferred and interact at the PVK/PFN-Br interface under an external electric field. The time for accumulation at this interface depends on the driving frequency. However, as already noted at high frequencies, the gate of the system allows only for field-generated carrier injection into the emitting volume, while at lower frequencies the gate allows for direct injection from the contacts. Nevertheless, both 
conditions result in charge drift toward the interface (illustrated in Fig. 1e). The electrons and holes are transferred to the heterointerface in the positive cycle of the AC electric field and drift along the opposite direction under the reverse bias $^{37-39}$. Therefore, the timedependent electric field generates an interfacial magnetic field at the PVK:Ir(MDQ) $)_{2}(\mathrm{acac}) / \mathrm{PFN}-\mathrm{Br}$ heterointerface according to Maxwell's equations. In an ideal case, the pixel dimension is $4 \times 4 \mathrm{~mm}^{2}$, which is significantly larger than its thickness $(\sim 300 \mathrm{~nm})$; hence, it is reasonable to ignore fringing effects (the infinite-area parallel-plate-capacitor assumption). Via engaging a highfrequency driving $(60,000 \mathrm{~Hz})$ under a strong $\mathrm{AC}$ electrical field $\left(1.6 \times 10^{8} \mathrm{~V} / \mathrm{m}\right)$, the temporal and spatial characteristics of the internal magnetic field are shown in Fig. 1f. The upper and lower half-planes represent the opposite "clock directions" of the magnetic field in the positive and negative halves of an AC cycle. The amplitude of the magnetic field is estimated to be approximately $0.85 \mathrm{mT}$. More details can be found in Supplemental Information, along with simulation results with various frequencies in Figure S3. The dynamic revolution of the magnetic field is shown in Movie S1.

The heterointerface also plays the role of an $\mathrm{e}-\mathrm{h}$ pair recombination zone for hot carrier injection, as shown in the energy-level diagram in Fig. 1g. These e-h pairs not only move in the applied electric field but also experience the induced magnetic field. The device shows a blue emission (in Figure S4) due to the PFN-Br fluorescence at near-DC driving $(50 \mathrm{~Hz})$ since the dissociation rate of $\mathrm{e}-\mathrm{h}$ pairs is negligible in the absence of an induced magnetic field $(<0.00005 \mathrm{mT})$. When this internal AC magnetic field is of the same order as the nuclear hyperfine field $(\sim 1 \mathrm{mT})$, ISC suppression should occur ${ }^{11}$ and this would naturally lead to singlet-spin e-h pair accumulation. Many secondary carriers are produced in PFN-Br through the magnetically mediated dissociation of the $\mathrm{e}-\mathrm{h}$ pairs. The secondary charges diffuse to nearby $\operatorname{Ir}(\mathrm{MDQ})_{2}(\mathrm{acac})$ sites, which yields decay of triplet-state excitons, as shown in Figure S4. There is no significant position shift of the recombination zone in the device, as shown in Figure S5. Thus, as illustrated in Fig. 1g, in the low-frequency driving regime $(50-1000 \mathrm{~Hz})$, hot carrier injection is the main mechanism for fluorescent excitons in PFN-Br. In the high-frequency regime $(30,000-70,000 \mathrm{~Hz})$, the highintensity AC magnetic field at the F-P interface populates singlet-excited $\mathrm{e}-\mathrm{h}$ pairs mostly via ISC suppression, which leads to secondary carriers. The secondary carriers exist in the form of bonded electrons in the PFN-Br polymer matrix, more specifically, with $\mathrm{Br}$ atoms, which are strong electron acceptors. The charged $\mathrm{Br}$ ions significantly improve the carrier diffusion length ${ }^{40}$, resulting in negative charges moving across the interfacial energy barrier. Consequently, the secondary carriers are transferred to $\operatorname{Ir}(\mathrm{MDQ})_{2}(\mathrm{acac})$ for red phosphorescent emission. For the same reason, the charged movable $\mathrm{Br}$ ions greatly facilitate magnetic field current, even under very subtle magnetic intensity with non-ionized polymer, which normally requires over hundreds of $\mathrm{mT}^{41}$. More discussion is presented in supplementary information.

Figure 2a, b show the evolution of the device's EL spectrum with increasing electric field at low and high frequencies. At the frequency of $50 \mathrm{~Hz}$, there are trivial spectral shifts in Fig. 2a when the applied voltage varies from 15.4 to $20.4 \mathrm{~V}$; however, no phosphorescence is observed. This is attributed to the dominant hot carrier injections, as shown in Fig. 2c. Electrons and holes are injected in the positive halves of voltage cycles while no current injection occurs in the reverse bias. Hot carrier injection is strongly related to the 474-nm-wavelength fluorescence.

For $60,000 \mathrm{~Hz}$ (secondary-carrier-related), as shown in Fig. 2b, the EL intensity of the fluorescent emission at 474 $\mathrm{nm}$ is nearly identical to that observed at $50 \mathrm{~Hz}$. However, the $595 \mathrm{~nm}$ phosphorescent peak grows as the external electric field increases. Examining current transients in Fig. $2 \mathrm{~d}$, the total current density is the sum of the rootmean-square (RMS) values of the sinusoidal waveform and the direct current (DC) offset $\left(J_{\text {tot }}=J_{\mathrm{dc}}+J_{\text {sine; }}\right.$ the method used for current component determination can be found in Supporting Information). Under the lower voltage of $17.9 \mathrm{~V}$, the DC current density and RMS sine current density are 60.2 and $36.6 \mathrm{~mA} / \mathrm{cm}^{2}$, respectively. Compared to higher voltages $(18.9,19.8,20.6,21.5$, and $22.0 \mathrm{~V})$, the DC current densities are dramatically increased to $82.3,114.9,138.5,164.1$, and $184.6 \mathrm{~mA} / \mathrm{cm}^{2}$ while relatively constant RMS sinusoidal currents of 37.8 , $39.4,42.1,43.7$, and $45.2 \mathrm{~mA} / \mathrm{cm}^{2}$, respectively, are observed. We suggest that the tremendous enhancement of the secondary charge current produces the growth of the 595-nm-wavelength phosphorescence.

In addition, $J_{\mathrm{rms}}-L-V_{\mathrm{rms}}$ characteristics at low frequency $(50 \mathrm{~Hz})$ and high frequency $(60,000 \mathrm{~Hz})$ are shown in Fig. 2e, in which the maximum brightnesses, namely, $360 \mathrm{~cd} / \mathrm{m}^{2}$ in blue and $600 \mathrm{~cd} / \mathrm{m}^{2}$ in red, are of the order that is necessary for devices for personal display use. Figure $2 \mathrm{f}$ shows the relation between $J_{\mathrm{rms}}$ and $L$ at the frequencies of $50 \mathrm{~Hz}$ and $60 \mathrm{kHz}$. The $50 \mathrm{~Hz}$ curve is fitted by a linear function, which has been widely demonstrated in the standard DC-driven organic light-emitting diodes (OLEDs). The linear fit strongly suggests that the exciton concentration inside the device remains below the level at which multi-exciton effects are dominant, such as Augur, quenching, and dissociation. In contrast, the $60 \mathrm{kHz}$ curve can be fitted not by a linear function but by a first-order exponential function, which indicates an improved exciton recombination efficiency, which rules out the Augur recombination and quenching effects. The exponential 
line fits the data in both the high- and low-current regimes, which suggests that the phosphorescent exciton recombination efficiency is independent of the exciton density. These triplets are again generated by the free carriers from the $\mathrm{e}-\mathrm{h}$ dissociation promoted by the $\mathrm{AC}$ magnetic-field-assisted ISC suppression. Therefore, rather than the injection efficiency, the AC field is the main factor that impedes the singlet-to-triplet ISC. In consequence, a higher power efficiency is achieved at 60,000 $\mathrm{Hz}(1.5 \mathrm{~lm} / \mathrm{W}$; details are shown in Figure S6).

The luminance-frequency characteristics of the colortunable AC-OEL device are shown in Fig. 3a. The total

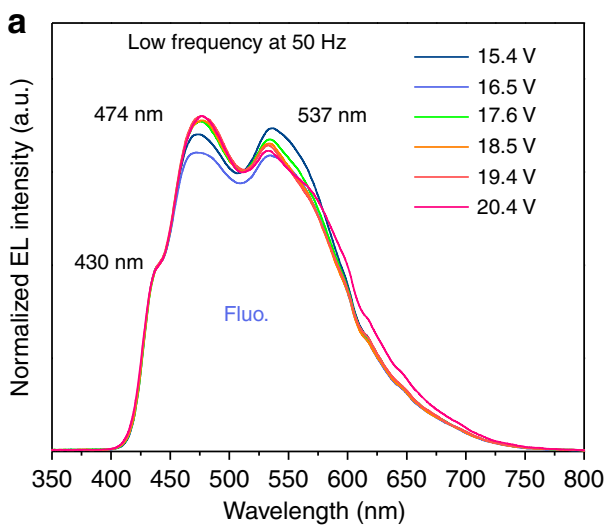

b
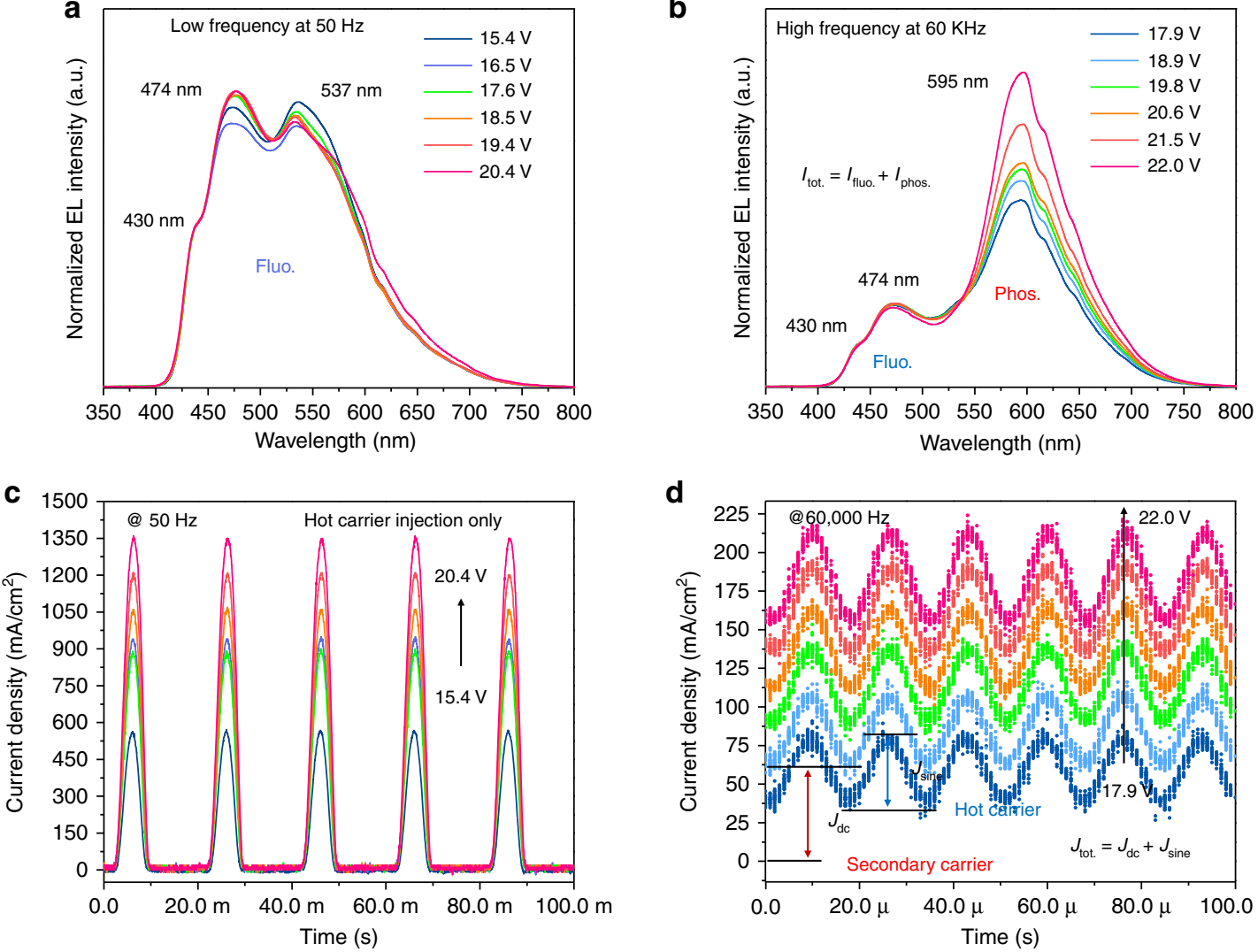

\section{d}
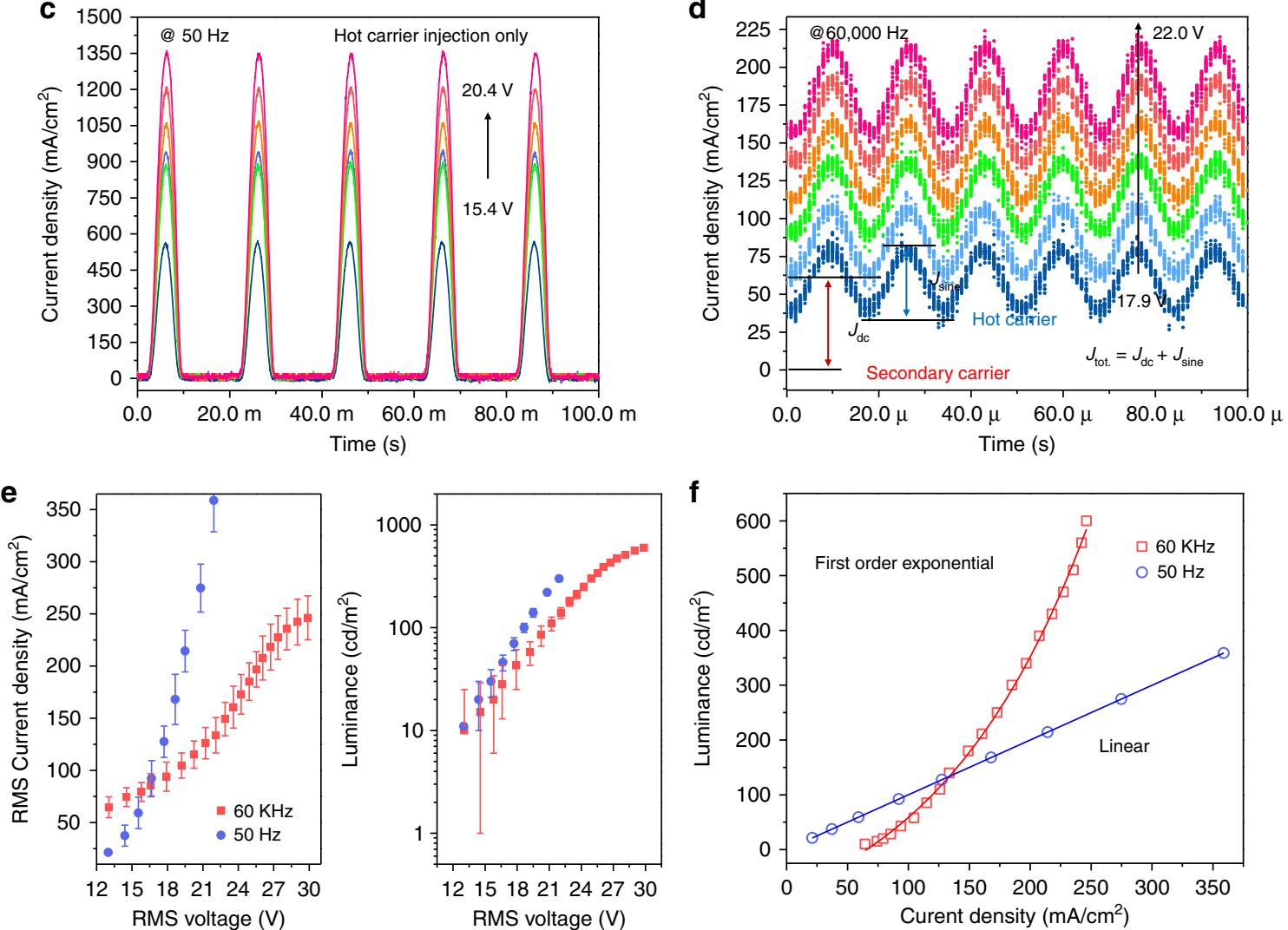

Fig. 2 Electroluminescence (EL) spectrum and current characteristic transients with increasing RMS voltage under 50 and $60,000 \mathrm{~Hz}$. a At $50 \mathrm{~Hz}$, the electroluminescence (EL) spectrum with RMS voltage varying from 15.4 to $20.4 \mathrm{~V}$, which correspond to luminances of $15-210 \mathrm{~cd} / \mathrm{m}^{2}$. Hot carrier injection is the only current contribution. b At $60,000 \mathrm{~Hz}$, the EL spectrum with RMS voltage varying from 17.9 to $22.0 \mathrm{~V}$, which correspond to luminances of $40-240 \mathrm{~cd} / \mathrm{m}^{2}$. c Time-resolved current at $50 \mathrm{~Hz}$. Hot carrier injection is the only current contribution. d Time-resolved current at $60,000 \mathrm{~Hz}$ with various voltages $(17.9-22.0 \mathrm{~V})$. Secondary carriers $\left(J_{\mathrm{dc}}\right)$ and hot injection carriers $\left(J_{\text {sine }}\right)$ have mutual contributions to the EL spectrum and current density characteristics. e $J_{\text {rms }}-V_{\text {rms }}$ and $L-V_{\text {rms }}$ characteristics of AC-OEL devices at 50 and $60,000 \mathrm{~Hz}$, respectively. $\mathbf{f} L$ Luminance as a function of current density at 50 and $60 \mathrm{kHz}$ 


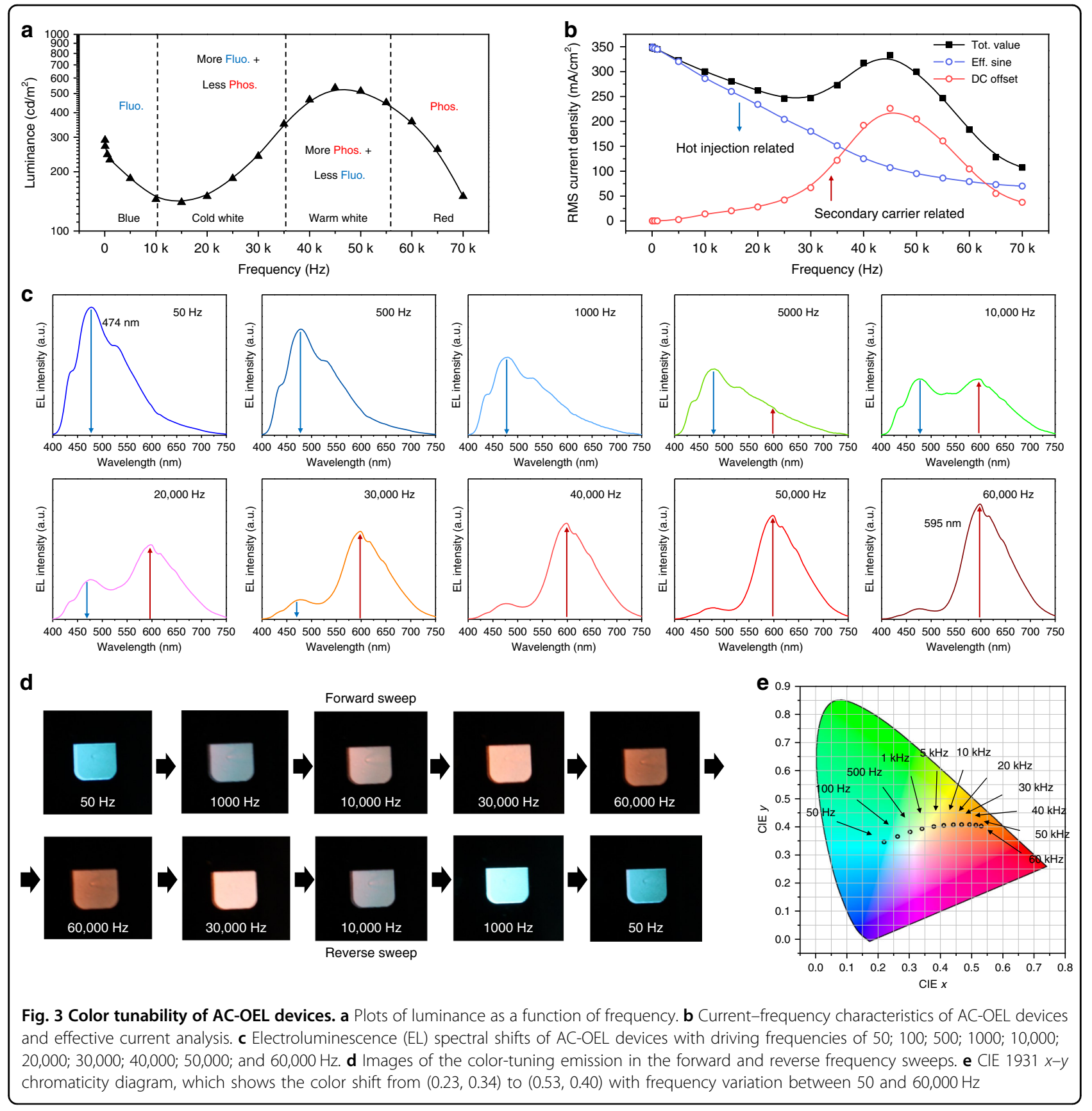

emission of the device shifts between the fluorescent and phosphorescent contributions, whereas the luminance is relatively stable over the frequency. Corresponding to the F-P shift, the frequency characteristics are also shown with respect to current density in Fig. 3b. Analyzing the low-frequency regime $(<1000 \mathrm{~Hz})$ first, low frequencies lead to dominant blue fluorescence since, as we suspected, the device under low-frequency driving acts more like a carrier-injection-type diode in the forward and reverse biases (Figure S7).
At higher frequencies $(>10,000 \mathrm{~Hz})$, the current density consists of a sinusoidal contribution and a DC offset (see Figure S7), essentially reflecting both the displacement of the direct current injection and the secondary charge current, respectively. In Fig. 3b, the DC offset component of the current through the device starts at a very low level $\left(13.8 \mathrm{~mA} / \mathrm{cm}^{2}\right)$ at $10,000 \mathrm{~Hz}$ and increases to $226.1 \mathrm{~mA} / \mathrm{cm}^{2}$ at $45,000 \mathrm{~Hz}$. In contrast, the RMS value of the sinusoidal component of the current waveform drops from $286.1 \mathrm{~mA} / \mathrm{cm}^{2}$ at $10,000 \mathrm{~Hz}$ to $106.8 \mathrm{~mA} / \mathrm{cm}^{2}$ at 
$45,000 \mathrm{~Hz}$, which suggests a significantly reduced contribution of hot carrier injection to the total current at high frequency. These opposite trends illustrate that an electric field of $>20,000 \mathrm{~Hz}$ applied to the capacitive device is sufficient to generate a magnetic field that is strong enough to yield secondary charge diffusion. The stronger AC magnetic field (due to higher frequency) suppresses ISC between singlet-state and triplet-state $\mathrm{e}-\mathrm{h}$ pairs in the $\mathrm{PFN}-\mathrm{Br}$, thereby resulting in population enhancement of singlet $\mathrm{e}-\mathrm{h}$ pairs at the $\mathrm{F}-\mathrm{P}$ interface. The elevated singlet-triplet ratio promotes the generation of secondary charge carriers. The hopping transport of secondary electrons and holes in the organic semiconductor is acutely tied to the generation of radical triplet excitons in $\operatorname{Ir}(\mathrm{MDQ})_{2}$ (acac), leading to red phosphorescence (as indicated in Fig. 3a). The coupling of the driver to the capacitive device has been taken into consideration by comparing the dominant capacitance of the device (1-3 nF) with the parallel external capacitance $(530 \mathrm{pF})$ in the driver. Driving frequencies of $>50,000 \mathrm{~Hz}$ cause insufficient carrier injection, resulting in the decrease in the number of $\mathrm{e}-\mathrm{h}$ pairs and the total current reduction in Fig. 3b.

In Fig. 3c, the EL spectrum of the AC-OEL device shows a dramatic color change when the driving field frequency varies from 50; $100 ; 500 ; 1000 ; 10,000 ; 20,000 ; 30,000$; 40,$000 ; 50,000 \mathrm{~Hz}$, up to $60,000 \mathrm{~Hz}$. The $474 \mathrm{~nm}$ emission band is dominant at the low frequency of $50 \mathrm{~Hz}$. As the driving frequency increases, the peaks at 430,474 , and $531 \mathrm{~nm}$ (due to PFN-Br's fluorescent emission) are weakened; in contrast, the $595 \mathrm{~nm}$ peak (which corresponds to $\operatorname{Ir}(\mathrm{MDQ})_{2}$ (acac)'s phosphorescent emission) grows rapidly and becomes the dominant emission band. All spectra are measured under $100 \mathrm{~cd} / \mathrm{m}^{2}$, integrated for 500 $\mathrm{ms}$ and averaged over 5 runs. The operating pixel images in Fig. 3d provide us with a clearer picture of the color change with frequency in the forward and reverse sweeps. As indicated by the marked circles, the CIE coordinates in Fig. 3e start from $(0.23,0.34)$ at $50 \mathrm{~Hz}$, cross the white zone, and reach $(0.53,0.40)$ in the red zone at $60,000 \mathrm{~Hz}$. Another graphic display of the AC-OEL pixel color change with driving frequency is shown in Movie S2. We also observed non-homogenous emission from the pixel, which is mainly attributed to two major mechanisms: the non-homogenous thin film of PFN-Br and the uniformity of the AC magnetic field coupling. The thin PFN-Br layer at the substrate edge has an $\mathrm{e}-\mathrm{h}$ generation zone close to the F-P interface, which facilitates the drift of the secondary charges, resulting in red emission. The AC field coupling is also spatially dependent, as shown in Fig. 1f, which suggests a stronger magnetic field at the substrate edge than at the center. Therefore, the spatially dependent magnetic field also leads to the red color shift that first occurs in the pixel area near the substrate edge. Further analysis of the non-homogenous emission can be found in Supplemental Information.

To further study the energy transition at the F-P interface, photoluminescence (PL) spectroscopy is performed, and the results are shown in Fig. 4a, b. The absorption of PFN-Br (peaks at $398 \mathrm{~nm}$ ) shows a large overlap with the PL spectra of the host PVK (which show a wide peak at $404 \mathrm{~nm}$ ) in Fig. 4a. This implies an efficient Förster energy transfer route between PVK and PFN-Br (Förster resonance energy transfer efficiency $\sim 21.1 \%$, calculated from Figure S8). In the PL spectra for PVK:3 wt $\% \operatorname{Ir}(\mathrm{MDQ})_{2}(\mathrm{acac}) / \mathrm{PFN}-\mathrm{Br}$ shown in Fig. 4b, an extra 585 $\mathrm{nm}$ peak due to $\operatorname{Ir}(\mathrm{MDQ})_{2}(\mathrm{acac})$ was detected when the sample was excited by $347 \mathrm{~nm}$ (PVK's strongest absorption); in contrast, under $380 \mathrm{~nm}$ excitation (PFN-Br's strongest absorption), this $585 \mathrm{~nm}$ peak is absent. This suggests that direct energy transfer between $\mathrm{PFN}-\mathrm{Br}$ and $\operatorname{Ir}(\mathrm{MDQ})_{2}(\mathrm{acac})$ is not allowed. The Förster energy transfer from PVK to PFN-Br and the forbidden transfer between PFN-Br and $\operatorname{Ir}(\mathrm{MDQ})_{2}(\mathrm{acac})$ explains the blue florescence that is due to PFN-Br in hot carrier injection.

Because of the full ionization of poly[ $\left(9,9-\mathrm{bis}\left(3^{\prime}-(\mathrm{N}, \mathrm{N}-\right.\right.$ dimethylamino)propyl)-2,7-fluorene)-alt-2,7-(9,9-dioctylfluorene)] (PFN-DOF) by $\mathrm{Br}$ atoms, $\mathrm{PFN}-\mathrm{Br}$ possesses many moveable negative charges among the main polymers. Figure 4c shows the electron mobility enhancement by the diffusive Br-negative ions compared with PFNDOF. The ionic conductivity is the most important property of solid polymer electrolyte. By introducing the $\mathrm{Br}$ ions into the PFN to form an electrolyte system, the magnitude of the conductivity will be enhanced. The conductivity of PFN-Br $\left(\sim 7.8 \times 10^{-7} \mathrm{~S} / \mathrm{cm}\right)$ is significantly improved compared to that of PFN-DOF $\left(\sim 3.1 \times 10^{-9} \mathrm{~S} /\right.$ $\mathrm{cm})$, which is due to the $\mathrm{Br}$-anion movements under the electric field. Because of the long-distance diffusion, the movable $\mathrm{Br}$ ions are able to populate the free secondary electrons, which leads to the dissociation of more excitons, thereby facilitating carrier diffusion to the phosphorescent emission layer. For comparison with PFN-Br devices, we studied the spectral shift in PFN-DOF devices between a magnetic-field-free device $(50 \mathrm{~Hz})$ and an ACmagnetic-field-coupled device $(60,000 \mathrm{~Hz})$ in the same architecture. In Fig. 4d, the fluorescence of PFN-DOF (at 423 and $476 \mathrm{~nm}$ ) is promoted, which implies the promotion of singlet-state excitons by suppressing ISC of PFN-DOF. However, the color change is almost unnoticeable in PFN-DOF, which suggests that the secondary carriers are unable to reach the phosphorescent sites without the aid of $\mathrm{Br}$ ions. More work about the magnetic field effect on PFN-DOF can be found in supplementary information and Figure S9. In the absence of a PFN-Br layer, the excitons still can be formed and recombined at the $\mathrm{p}-\mathrm{n}$ interface. However, the extremely low radiative recombination rate of $\mathrm{TPBi}$ facilitates exciton decay 
a

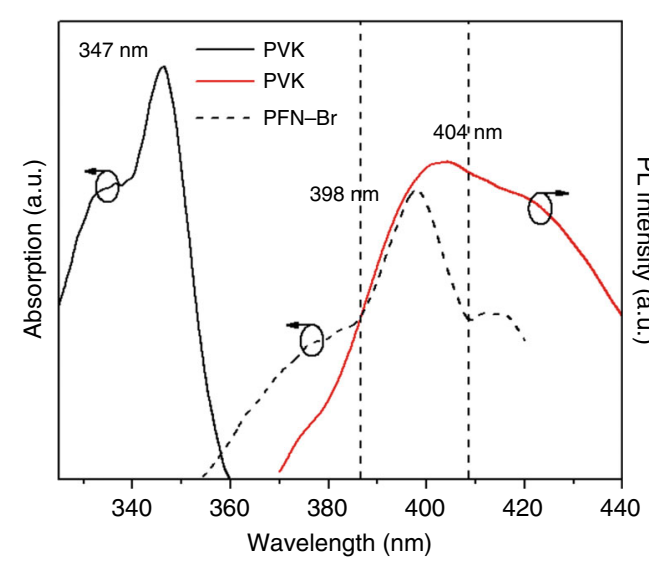

C

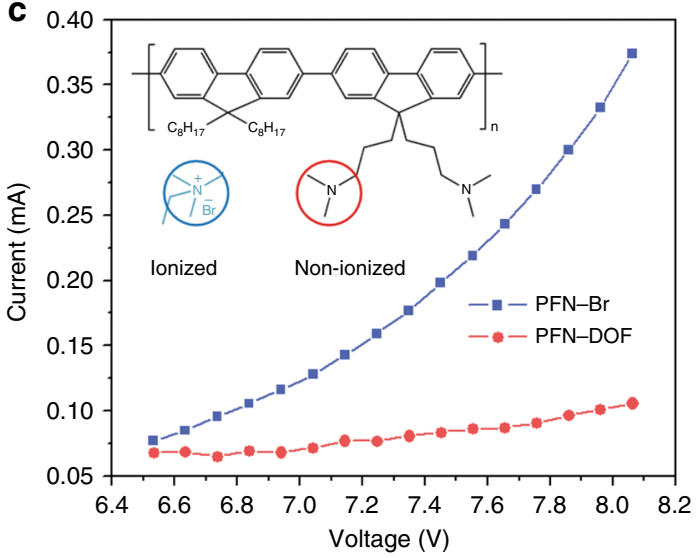

b

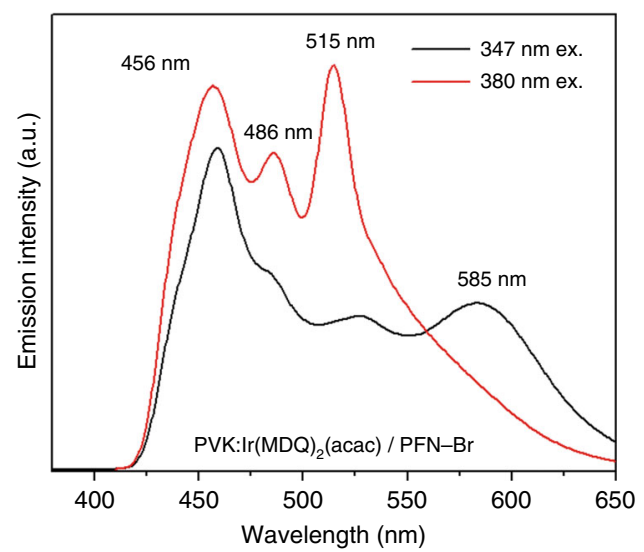

d

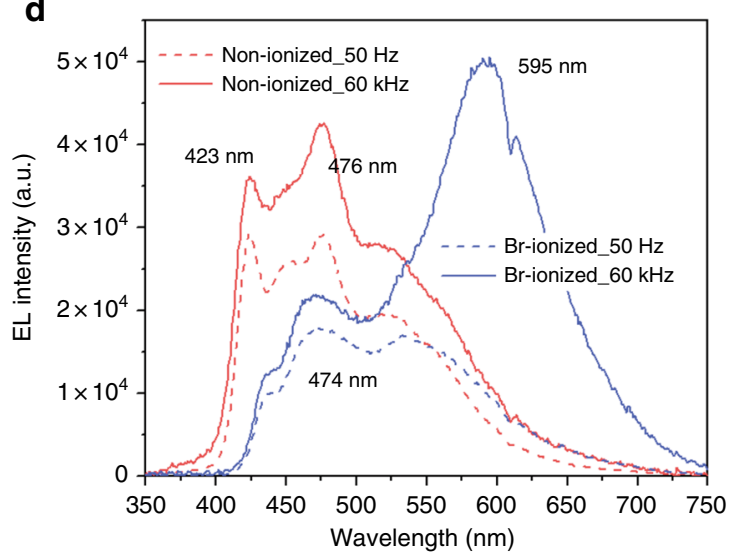

Fig. 4 Photoluminescence (PL) spectroscopy for organic light emitting materials and energy transfer analysis. a Excitation and emission spectra for PVK film and PFN-Br film on glass. b PL spectra for glass/PVK:3 wt $\%$ Ir(MDQ) 2 (acac)/PFN-Br with two excitation wavelengths : $347 \mathrm{~nm}$ and $380 \mathrm{~nm}$. c Current-voltage characteristics of PFN-Br (ionized) and PFN-DOF (non-ionized). d EL spectral shifts of PFN-Br (ionized) and PFN-DOF (nonionized) at $50 \mathrm{~Hz}$ (magnetic-free) and $60,000 \mathrm{~Hz}$ (magnetic-engaged)

directly at the $\operatorname{Ir}(\mathrm{MDQ})_{2}(\mathrm{acac})$ phosphorescent sites and the PVK fluorescent host, which was demonstrated by the EL spectra in Figure S10.

\section{Discussion}

Figure 5a shows the overall energy transfer at the PVK: $\operatorname{Ir}(\mathrm{MDQ})_{2}(\mathrm{acac}) / \mathrm{PFN}-\mathrm{Br}$ heterojunction. There are three processes that must be addressed:

1. ISC of $\mathrm{e}-\mathrm{h}$ pairs in PFN-Br is magnetic-fieldsensitive. In the presence of a magnetic field, energetically inaccessible $\mathrm{T}-$ and $\mathrm{T}+$ states yield a redistribution of singlet and triplet excited states $\left(\mathrm{S}_{0}\right.$ : $\left.\mathrm{T}_{0}=1 / 2: 1 / 2\right)$ in PFN-Br, as has been predicted theoretically ${ }^{41-46}$,

2. Accumulated singlet-spin $\mathrm{e}-\mathrm{h}$ pairs are dissociated into diffusive secondary carriers with the assistance of $\mathrm{Br}$ ions;

3. The energy transfer of e-h pairs between PVK and $\mathrm{PFN}-\mathrm{Br}$ is efficient but negligible because of the insufficient number of singlet-state excitons in PVK.
The AC magnetic field is only present in the highfrequency electric field. The magnetic field influences the ratio of singlet and triplet spin excitons at the $p-n$ junction where $\mathrm{e}-\mathrm{h}$ pairs are generated from the injected carriers. As a consequence, the 1:3 singlet-triplet ratio is violated and the singlet spin exciton accumulation occurs in the fluorescent emission layer. In contrast, it is believed that the exciton generation at the $\mathrm{p}-\mathrm{n}$ interface would not be affected by the AC field due to the constant exciton generation zone.

An instructive and elegant confirmation of the magnetic field effects on F-P tunable emission can be obtained through the use of $\mathrm{Fe}_{3} \mathrm{O}_{4}$ magnetic NPs as a magnetic field alternative. The nano-magnetite-induced magnetic field is extremely local; hence, it will not introduce extra, unpredicted magnetic field effects as a uniform external magnetic field may do (for instance, possible magnetic field effects on the PVK). Moreover, it has been reported that magnetic field gradients due to $\mathrm{Fe}_{3} \mathrm{O}_{4}$ nanocrystals are more effective in suppressing ISC processes than static 


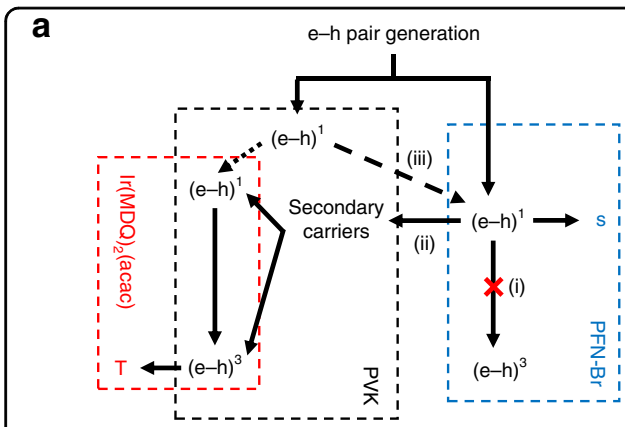

d

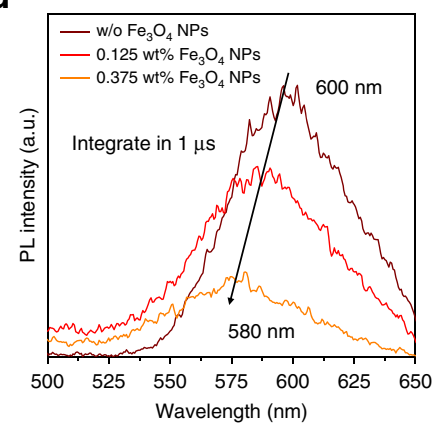

f

Wavelength $(\mathrm{nm})$

$350 \quad 400450500 \quad 550 \quad 600 \quad 650$

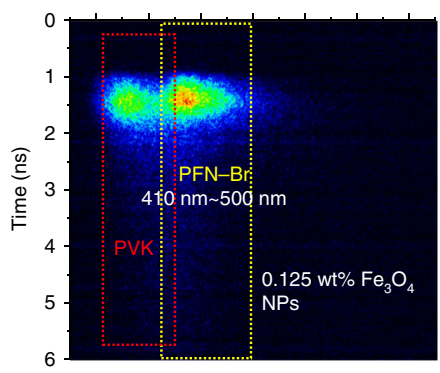

b

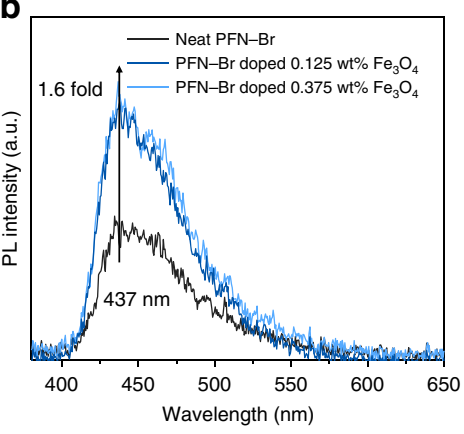

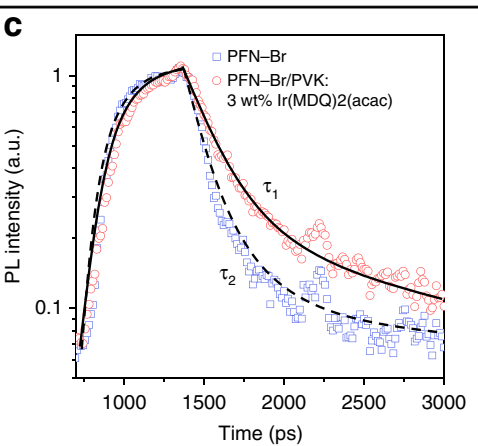

h e

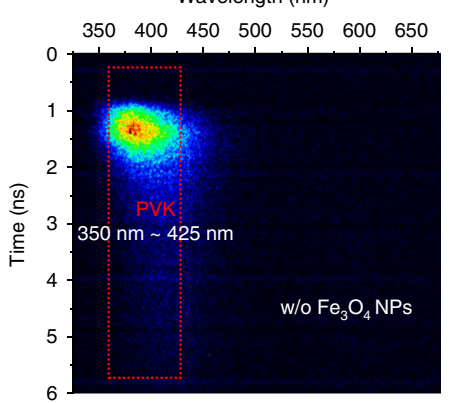

\section{g}

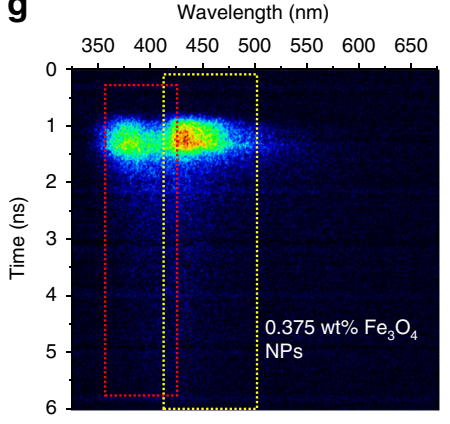

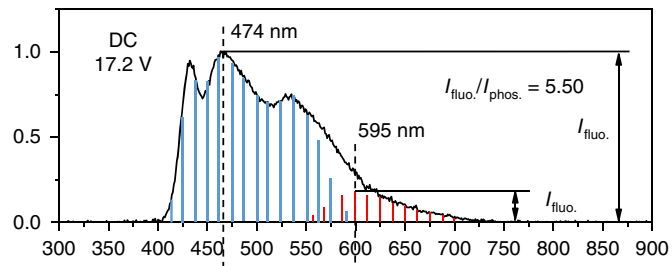
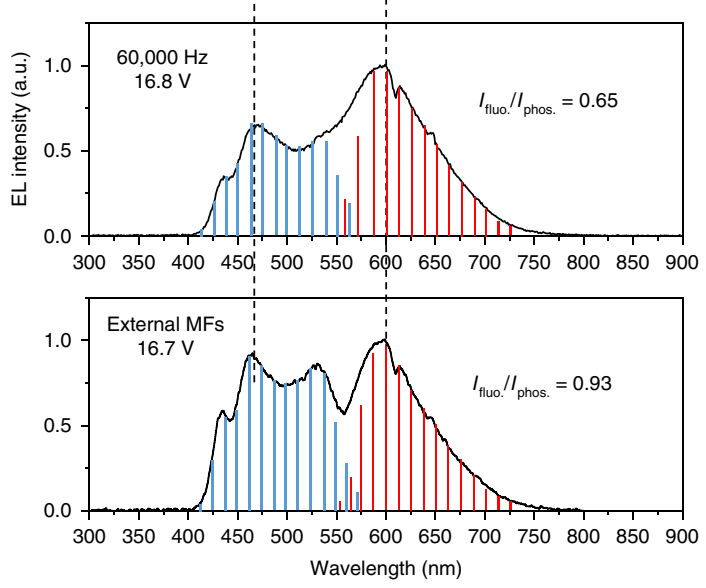

Fig. 5 Energy transfer analysis for the fluorescence-phosphorescence (F-P) emission unit in the presence of magnetic field effect. a Schematic diagram of e-h pair excited energy transfer mechanisms among PVK (host), Ir(MDQ) 2 (acac) (phosphorescent dopant), and PFN-Br (fluorescent material) with magnetic-suppressive ISC. (e-h) ${ }^{1}$ and $(e-h)^{3}$ represent singlet and triplet intermolecular e-h pairs. S and T are singlet and triplet excitons. b Time-integrated PL spectra that were measured at $437 \mathrm{~nm}$ for pure PFN-Br thin film, PFN-Br doping 0.125 wt $\% \mathrm{Fe}_{3} \mathrm{O}_{4} \mathrm{NP}$ film, and PFN-Br doping $0.375 \mathrm{wt} \% \mathrm{Fe}_{3} \mathrm{O}_{4} \mathrm{NP}$ film after constant excitation at $280 \mathrm{~nm}\left(10 \mathrm{~Hz}, 500 \mathrm{fs}\right.$, and $\left.130 \mathrm{\mu J} / \mathrm{cm}^{2}\right)$. c Time-resolved PL decay transients at

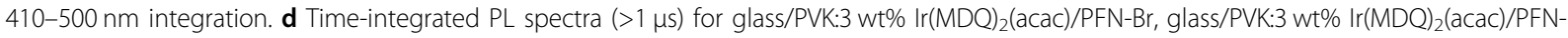
Br:0.125 wt $\% \mathrm{Fe}_{3} \mathrm{O}_{4}$, and glass/PVK:3 wt\% $\operatorname{Ir}(\mathrm{MDQ})_{2}(\mathrm{acac}) / \mathrm{PFN}-\mathrm{Br}: 0.375 \mathrm{wt} \% \mathrm{Fe}_{3} \mathrm{O}_{4}$. The streak images for glass/PVK:3 wt $\% \operatorname{Ir}(\mathrm{MDQ})_{2}(\mathrm{acac}) / \mathrm{PFN}-\mathrm{Br}(\mathbf{e})$, glass/PVK:3 wt \% Ir(MDQ) 2 (acac)/PFN-Br:0.125 wt\% $\mathrm{Fe}_{3} \mathrm{O}_{4}(\mathbf{f})$, and glass/PVK:3 wt\% Ir(MDQ) ${ }_{2}(\mathrm{acac}) / \mathrm{PFN}-\mathrm{Br}: 0.375$ wt $\% \mathrm{Fe}_{3} \mathrm{O}_{4}$ (g) for $6 \mathrm{~ns}$. $\mathbf{h}$ EL spectra with no magnetic field, internal $\mathrm{AC}$ magnetic field, and external magnetic field due to $\mathrm{Fe}_{3} \mathrm{O}_{4} \mathrm{NPs}$

external fields for DC devices ${ }^{1,42}$. The ferromagnetic $\mathrm{Fe}_{3} \mathrm{O}_{4}$ magnetic NPs used here have an average diameter of $30 \mathrm{~nm}$ (Figure S11), which has been demonstrated by the X-ray diffraction (XRD) pattern (Figure S12), and are widely accepted as a ferromagnetic material since superparamagnetic behavior only exists in $\mathrm{Fe}_{3} \mathrm{O}_{4}$ magnetic NPs with diameters of $<10 \mathrm{~nm}^{47-49}$.

The 1.6-fold magnetic-field-enhanced singlet-state excitons in PFN-Br were directly observed in timeintegrated PL spectra in Fig. 5b, while 0.125 wt\% $\mathrm{Fe}_{3} \mathrm{O}_{4}$ NPs was doped in PFN-Br. A slight PL intensity increase is observed in $0.375 \mathrm{wt} \% \mathrm{Fe}_{3} \mathrm{O}_{4} \mathrm{NP}$-doped PFN-Br, indicating the $50 \%$ theoretical upper limit of singlet excitons. A constant excitation was used in the experiment: $\lambda_{\text {ex. }}=$ $280 \mathrm{~nm}$. In Fig. 5c, we show the picosecond-transient PL intensity of PVK:Ir(MDQ) $)_{2}$ (acac)/PFN-Br $\left(\tau_{1}=319.7 \mathrm{ps}\right.$, where $\tau_{0}$ is the time required for the PL to fall to $1 / e$ of the initial intensity) and PFN-Br $\left(\tau_{2}=171.7 \mathrm{ps}\right)$ for $410-500$ $\mathrm{nm}$ emission (which corresponds to PFN-Br's fluorescence). We attribute the PL radiative delay to the short exciton diffusion in PFN-Br, which has a negligible impact on $\operatorname{Ir}(\mathrm{MDQ})_{2}(\mathrm{acac})$ 's phosphorescence. Furthermore, the 
relatively reduced PL intensity of $\operatorname{Ir}(\mathrm{MDQ})_{2}$ (acac)'s phosphorescent emission $(580 \mathrm{~nm}-600 \mathrm{~nm})$ in Fig. 5d provides evidence that no diffusive exciton is involved in color tunability even though singlet-state excitons are saturated with doping magnetic NPs in PFN-Br. Therefore, the possibility of diffusive excitons crossing the interface is excluded; in contrast, Br-ion-enhanced secondary carriers are demonstrated. In addition, we analyzed the streak image for the sample of PVK:3 wt\% Ir $(\mathrm{MDQ})_{2}$ (acac)/PFN-Br in Fig. 5e. No emission is observed except for an intense emission band (350-425 nm), which corresponds to PVK's fluorescence. However, PFN-Br's fluorescent emission $(410-500 \mathrm{~nm})$ becomes observable when $0.125 \mathrm{wt} \% \mathrm{Fe}_{3} \mathrm{O}_{4}$ (Fig. 5f) or $0.375 \mathrm{wt} \% \mathrm{Fe}_{3} \mathrm{O}_{4}$ (Fig. 5g) are blended into PFN-Br. This result demonstrates that massive numbers of radical singlet-spin pairs are formed in PFN-Br due to the influence of the magnetic field on the F-P emitting unit. $\operatorname{Ir}(\mathrm{MDQ})_{2}$ (acac)'s phosphorescent emission cannot be captured in the first several nanoseconds in either case because of long-lived triplet excitons but appears at $600 \mathrm{~nm}$ in time-integrated spectra, as shown in Figure S13.

To confirm the importance of the magnetic effect on the F-P emitting unit, we measured the EL spectra of analogous devices (the device structures are described in detail in Figure S14) in Fig. 5h with zero magnetic field coupling (DC driving), internal AC magnetic field $(60,000-\mathrm{Hz}$ driving), and external NP magnetic field (DC driving). A large F-P intensity ratio $\left(I_{\mathrm{f}} / I_{\mathrm{p}}\right)$ of 5.5 was observed when the magnetic field was eliminated. In contrast, the F-P intensity ratios are 0.65 and 0.93 in the $\mathrm{AC}$ magnetic field and $\mathrm{Fe}_{3} \mathrm{O}_{4} \mathrm{NC}$ magnetic field, respectively. This implies that the low $\mathrm{F}-\mathrm{P}$ intensity ratio is evidence that secondary charges, which originate from singlet $\mathrm{e}-\mathrm{h}$ pair accumulation, are able to facilitate the generation of triplet excitons in the $\operatorname{Ir}(\mathrm{MDQ})_{2}(\mathrm{acac})$ molecules.

In summary, the application of internally generated $\mathrm{AC}$ magnetic fields in a unique AC-OEL architecture is demonstrated to be an efficient method for manipulating the ratio of singlet- and triplet-spin pairs. The magnetically sensitive ISC can modify the probability of singletspin e-h pairs in organics (PFN-Br), which significantly populates diffusive secondary charges to achieve phosphorescence emission $\left(\operatorname{Ir}(\mathrm{MDQ})_{2}(\mathrm{acac})\right)$. By varying $\mathrm{AC}$ magnetic fields that are coupled at an F-P heterointerface in the AC-OEL device, the emission can be shifted between blue fluorescence (singlet-spin-related) and red phosphorescence (triplet-spin-related) with no significant brightness changes. Conventional contributions to color shifts that are associated with spatial shifting of recombination zones or exciton redistribution and quenching under high voltage have been excluded by our experiments. While the unusual properties of magnetically coupled AC-OEL devices may lead to other breakthrough devices, our work opens new doors to a more detailed understanding of radical-pair manipulation in the quantum electrodynamics and spintronics of organic materials.

\section{Materials and methods \\ Materials and device fabrication}

The AC-OEL devices were built on a $2.54 \times 2.54 \mathrm{~cm}^{2}$ glass substrate precoated with a 140 -nm-thick layer of ITO with a sheet resistance of $\sim 10 \mathrm{ohms}$ per square. The ITO glass substrate was cleaned in an ultrasonic bath with acetone followed by methanol and isopropanol for $1 \mathrm{~h}$ each and dried in vaccum oven for 2 hours. Before spincoating, the ITO substrates were exposed in UV-ozone for $30 \mathrm{~min}$. To efficiently control the carrier transport under AC driving, PEDOT:PSS doped with $18 \mathrm{wt} \% \mathrm{ZnO}$ NPs $(\sim 35 \mathrm{~nm})$ was spun onto the substrate to form a gate-andhole-generation layer. For the dual-emission-layer unit, a layer of PVK with $3 \mathrm{wt} \% \operatorname{Ir}(\mathrm{MDQ})_{2}$ (acac) was spin-coated in chlorobenzene at a concentration of $10 \mathrm{mg} / \mathrm{mL}$ at 2000 $\mathrm{rpm}$, followed by baking at $100^{\circ} \mathrm{C}$ for $30 \mathrm{~min}$. The second emission layer was obtained by spin coating the $5 \mathrm{mg} / \mathrm{mL}$ $(20 \mathrm{~nm}), 8 \mathrm{mg} / \mathrm{mL}(50 \mathrm{~nm})$, or $10 \mathrm{mg} / \mathrm{mL}(70 \mathrm{~nm}) \mathrm{PFN}-\mathrm{Br}$ blends in methanol at $3000 \mathrm{rpm}$ and dried at $95^{\circ} \mathrm{C}$ for 20 min. Iron oxide magnetic nanopowder $\left(\mathrm{Fe}_{3} \mathrm{O}_{4} \mathrm{NPs} \sim 30\right.$ $\mathrm{nm})$ was purchased from Sigma-Aldrich and was prefunctionalized by $N$-succinimidyl ester for easy dispersion in a suitable solvent. A $40 \mathrm{~nm}$ electron-transport material (TPBi) and a $150 \mathrm{~nm}$ top $\mathrm{Al}$ electrode were deposited by thermal evaporation through a shadow mask with a 0.16 $\mathrm{cm}^{2}$ opening at the rates of 0.2 and $2 \AA / \mathrm{s}$, respectively. Before testing, the devices were sealed by quartz caps with UV curing adhesive in nitrogen atmosphere in a glove box.

\section{Device EL and PL measurement}

The AC-OEL devices were measured in ambient air at atmospheric pressure and room temperature $\left(25^{\circ} \mathrm{C}\right)$ with encapsulation. A $200 \mathrm{MHz}$ function/arbitrary waveform generator (Agilent 33220A) connected to an amplifier (Trek PZD700A M/S) provided a sinusoidal signal with suitable voltage and frequency. A power analyzer (Zimmer LMG95) was utilized to read the RMS values of voltage and current on the AC-OEL devices. At the same time, voltage waveforms and current waveforms were recorded by a Tektronix TPS 2024B oscilloscope to validate the voltage and current values. The method that we used to determine the AC and DC current components is described in detail in Supplemental Information. A photometer (ILT 1400-A) was used to measure the outcoupling luminance. The entire system was connected and controlled by a computer. To obtain accurate and reliable measurements of luminance, each turn-on measurement of the pixels was integrated over $2000 \mathrm{~ms}$ and averaged 5 times instead of fast sweeping to yield goodlooking curves. The EL spectra for color-tunable AC-OEL 
devices were collected by an ILT 950 spectroradiometer (International Light Technologies) while the driving frequency was varied easily by a function waveform generator. The PL spectra for PVK, PFN-Br, and PVK:Ir $(\mathrm{MDQ})_{2}(\mathrm{acac}) / \mathrm{PFN}-\mathrm{Br}$ thin films were measured by a fluorescence spectrometer (PerkinElmer LS50B).

\section{Streak camera test}

For measurement of the transient PL characteristics, short-pulse excitation with a pulse width of $200 \mathrm{fs}$ and a wavelength of $280 \mathrm{~nm}$ was used in combination with a Hamamatsu C2830 streak camera system that mainly consisted of a C2830 streak camera and an M2547 fast sweep unit (resolution $<10 \mathrm{ps}$ ). F-P lifetime measurements were carried out via a photodiode with UV laser illumination in dark-room ambient at $25^{\circ} \mathrm{C}$.

\section{Transmission electron microscopy (TEM) and atomic force microscopy (AFM) images}

A TEM (JEOL JEM-1200EX) was utilized to analyze the morphology of $\mathrm{Fe}_{3} \mathrm{O}_{4}$ NPs dispersed in PFN-Br methanol solution. The surface morphology analyses of PVK and PFN-Br were performed using an AFM (Asylum Research MFP-3D-BIO).

\section{X-ray diffraction (XRD) pattern}

The crystalline phase analysis was performed using an $\mathrm{X}$-ray powder diffractometer (Bruker D2 PHASER) in ambient. The result was averaged over 10 measurements.

\section{Acknowledgements \\ We thank Prof. R.T. Williams, D.R Onken, and Dr. K.B. Ucer for access to the streak camera in Olin laboratory at Wake Forest University. We acknowledge $H$. Lee for assistance with the atomic force microscopy test. We thank Dr. Y. Zheng for help with the XRD test. We acknowledge the financial support and use of equipment from the Center for Nanotechnology and Molecular Materials at Wake Forest University. Research funding was also provided through NSF grant ECCS-1610641.}

\section{Author details \\ ${ }^{1}$ Center for Nanotechnology and Molecular Materials, Wake Forest University, Winston-Salem, NC 27109, USA. ${ }^{2}$ Department of Physics, Wake Forest University, Winston-Salem, NC 27106, USA. ${ }^{3}$ Key Laboratory of Luminescence and Optical Information (Ministry of Education), Institute of Optoelectronics Technology, Beijing Jiaotong University, 100044 Beijing, P.R. China. ${ }^{4}$ Department of Electro-Optics, School of Engineering, University of Dayton, Dayton, OH 45469, USA. ${ }^{5}$ Department of Mathematics, Wake Forest University, Winston-Salem, NC 27106, USA. ${ }^{6}$ State Key Laboratory for Modification of Chemical Fibers and Polymer Materials, 201620 Shanghai, P.R. China. ${ }^{7}$ College of Materials Science and Engineering, Donghua University, 201620 Shanghai P.R. China. ${ }^{8}$ Institute of Advanced Materials, Nanjing Tech University, 211816 Nanjing, Jiangsu, P.R. China. ${ }^{9}$ Present address: Department of Physics and Astronomy, College of Charleston, Charleston, SC 29424, USA}

\section{Author' contributions}

J.X. and D.C. designed the experiments and performed the theoretical analysis. J.X. fabricated and tested the devices and performed the data analysis. J.X. and Y.C. carried out the photoluminescence test and performed the energy transfer mechanism analysis. G.S. prepared the materials used in this work and maintained the equipment. J.X. and P.L. performed the streak camera test and transient photoluminescence analysis. C.D. and J.X. conducted the microscope and XRD analyses. J.X. and L.S. optimized the performance of the color-tunable AC-OEL pixels. J.X., Y.G., H.W., and Y.C. discussed the results. J.X. and D.C. wrote the paper. D.C. planned and supervised the entire project. All authors discussed the results and reviewed the manuscript.

\section{Conflict of interest}

The authors declare that they have no conflict of interest.

Supplementary information is available for this paper at https://doi.org/ 10.1038/s41377-018-0046-5.

Received: 7 February 2018 Revised: 4 June 2018 Accepted: 5 June 2018 Accepted article preview online: 27 June 2018

Published online: 01 August 2018

\section{References}

1. Tang, C. W. \& VanSlyke, S. A. Organic electroluminescent diodes. Appl. Phys. Lett. 51, 913-915 (1987).

2. Friend, R. H. et al. Electroluminescence in conjugated polymers. Nature $\mathbf{3 9 7}$ 121-128 (1999).

3. Pope, M., Kallmann, H. P. \& Magnante, P. Electroluminescence in organic crystals. J. Chem. Phys. 38, 2042-2043 (1963).

4. Baldo, M. A., O'Brien, D. F., Thompson, M. E. \& Forrest, S. R. Excitonic singlettriplet ratio in a semiconducting organic thin film. Phys. Rev. B 60, 14422-14428 (1999).

5. Adachi, C., Baldo, M. A., Thompson, M. E. \& Forrest, S. R. Nearly $100 \%$ interna phosphorescence efficiency in an organic light-emitting device. J. Appl. Phys. 90, 5048-5051 (2001)

6. Baldo, M. A. et al. Highly efficient phosphorescent emission from organic electroluminescent devices. Nature 395, 151-154 (1998).

7. Kawamura, Y. et al. $100 \%$ phosphorescence quantum efficiency of Ir (III) complexes in organic semiconductor films. Appl. Phys. Lett. 86, 071104 (2005).

8. Forget, S. \& Chénais, S. Organic Solid-State Lasers (Springer, Berlin, Heidelberg, 2013).

9. Bobbert, P. A. Manipulating spin in organic spintronics. Science $\mathbf{3 4 5}$ 1450-1451 (2014).

10. $\mathrm{Hu}, \mathrm{B} . \& \mathrm{Wu}, \mathrm{Y}$. Tuning magnetoresistance between positive and negative values in organic semiconductors. Nat. Mater. 6, 985-991 (2007).

11. Nguyen, T. D., Gautam, B. R., Ehrenfreund, E. \& Vardeny, Z. V. Magnetoconductance response in unipolar and bipolar organic diodes at ultrasmall fields. Phys. Rev. Lett. 105, 166804 (2010).

12. Bobbert, P. A., Nguyen, T. D., van Oost, F. W. A., Koopmans, B. \& Wohlgenannt, M. Bipolaron mechanism for organic magnetoresistance. Phys. Rev. Lett. 99, 216801 (2007).

13. $W u, Y ., X u, Z$. H., Hu, B. \& Howe, J. Tuning magnetoresistance and magneticfield-dependent electroluminescence through mixing a strong-spin-orbitalcoupling molecule and a weak-spin-orbital-coupling polymer. Phys. Rev. B 75, 035214 (2007).

14. Mahato, R. N. et al. Ultrahigh magnetoresistance at room temperature in molecular wires. Science 341, 257-260 (2013).

15. Prigodin, V. N., Bergeson, J. D., Lincoln, D. M. \& Epstein, A. J. Anomalous room temperature magnetoresistance in organic semiconductors. Synth. Met. 156, 757-761 (2006).

16. Janssen, P. et al. Tuning organic magnetoresistance in polymer-fullerene blends by controlling spin reaction pathways. Nat. Commun. 4, 2286 (2013).

17. Kalinowski, J., Szmytkowski, J. \& Stampor, W. Magnetic hyperfine modulation of charge photogeneration in solid films of Alq3. Chem. Phys. Lett. 378, 380-387 (2003)

18. Wilkinson, J., Davis, A. H., Bussmann, K. \& Long, J. P. Evidence for charge-carrier mediated magnetic-field modulation of electroluminescence in organic lightemitting diodes. Appl. Phys. Lett. 86, 111109 (2005).

19. Müller, J. G. et al. Ultrafast dynamics of charge carrier photogeneration and geminate recombination in conjugated polymer: fullerene solar cells. Phys. Rev. B 72, 195208 (2005).

20. Szmytkowski, J., Stampor, W., Kalinowski, J. \& Kafafi, Z. H. Electric field-assisted dissociation of singlet excitons in tris-(8-hydroxyquinolinato) aluminum (III). Appl. Phys. Lett. 80, 1465 (2002). 
21. Stampor, W. Electromodulation of fluorescence in hole-transporting materials (TPD, TAPC) for organic light-emitting diodes. Chem. Phys. 256, 351-362 (2000).

22. Kalinowski, J. et al. Coexistence of dissociation and annihilation of excitons on charge carriers in organic phosphorescent emitters. Phys. Rev. B 74, 085316 (2006).

23. Wittmer, M. \& Zschokke-Gränacher, I. Exciton-charge carrier interactions in the electroluminescence of crystalline anthracene. J. Chem. Phys. 63, 4187-4194 (1975).

24. Tolstov, I. V. et al. On the role of magnetic field spin effect in photoconductivity of composite films of MEH-PPV and nanosized particles of PbS. J. Lumin. 112, 368-371 (2005).

25. Levinson, J., Weisz, S. Z., Cobas, A. \& Rolón, A. Determination of the triplet exciton-trapped electron interaction rate constant in anthracene crystals. J. Chem. Phys. 52, 2794-2795 (1970).

26. Shen, Z. L., Burrows, P. E., Bulović, V., Forrest, S. R. \& Thompson, M. E. Three-color, tunable, organic light-emitting devices. Science 276, 2009-2011 (1997).

27. Fröbel, M. et al. Get it white: color-tunable AC/DC OLEDs. Light Sci. Appl. 4, e247 (2015)

28. Berggren, M. et al. Light-emitting diodes with variable colours from polymer blends. Nature 372, 444-446 (1994)

29. Al Attar, H. A., Monkman, A. P., Tavasli, M., Bettington, S. \& Bryce, M. R. White polymeric light-emitting diode based on a fluorene polymer/lr complex blend system. Appl. Phys. Lett. 86, 121101 (2005).

30. Parthasarathy, G., Gu, G. \& Forrest, S. R. A full-color transparent metal-free stacked organic light emitting device with simplified pixel biasing. Adv. Mater. 11, 907-910 (1999).

31. Xu, J. W., Carroll, D. L., Smith, G. M., Dun, C. C. \& Cui, Y. Achieving high performance in AC-field driven organic light sources. Sci. Rep. 6, 24116 (2016).

32. $\mathrm{Xu}, \mathrm{J}$. W. et al. Layered, nanonetwork composite cathodes for flexible, highefficiency, organic light emitting devices. Adv. Funct. Mater. 25, 4397-4404 (2015).

33. Chen, Y. H., Xia, Y. D., Smith, G. M. \& Carroll, D. L. Frequency-dependent, alternating current-driven, field-induced polymer electroluminescent devices with high power efficiency. Adv. Mater. 26, 8133-8140 (2014).

34. Perumal, A. et al. Novel approach for alternating current (AC)-driven organic light-emitting devices. Adv. Funct. Mater. 22, 210-217 (2012).

35. Tian, Y., Xu, X. J., Wang, J. S., Yao, C. \& Li, L. D. Solution-processed white organic light-emitting diodes with enhanced efficiency by using quaternary ammonium salt doped conjugated polyelectrolyte. ACS Appl. Mater. Interfaces 6, 8631-8638 (2014)

36. Huang, F., Wu, H. B., Wang, D. L., Yang, W. \& Cao, Y. Novel electroluminescent conjugated polyelectrolytes based on polyfluorene. Chem. Mater. 16, 708-716 (2004).

37. Khramtchenkov, D. V., Arkhipov, V. I. \& Bässler, H. Charge carrier recombination in organic bilayer electroluminescent diodes. I. Theory. J. Appl. Phys. 81, 6954-6962 (1997).

38. Jonda, C. \& Mayer, A. B. R. Investigation of the electronic properties of organic light-emitting devices by impedance spectroscopy. Chem. Mater. 11 2429-2435 (1999).

39. Pingree, L. S. C., Scott, B. J., Russell, M. T., Marks, T. J. \& Hersam, M. C. Negative capacitance in organic light-emitting diodes. Appl. Phys. Lett. 86, 073509 (2005).

40. Luo, H. W. et al. Remarkable enhancement of charge carrier mobility of conjugated polymer field-effect transistors upon incorporating an ionic additive. Sci. Adv. 2, e1600076 (2016).

41. Wang, J. P., Chepelianskii, A., Gao, F. \& Greenham, N. C. Control of exciton spin statistics through spin polarization in organic optoelectronic devices. Nat. Commun. 3, 1191 (2012).

42. Cohen, A. E. Nanomagnetic control of intersystem crossing. J. Phys. Chem. A 113, 11084-11092 (2009).

43. Manolopoulos, D. E. \& Hore, P. J. An improved semiclassical theory of radical pair recombination reactions. J. Chem. Phys. 139, 124106 (2013).

44. Thomas, J. K. Excited states and reactions in liquids. Ann. Rev. Phys. Chem. 21, 17-38 (1970).

45. Ding, B. F. et al. Magnetic field modulated exciton generation in organic semiconductors: an intermolecular quantum correlated effect. Phys. Rev. B 82, 205209 (2010).

46. Song, J. Y., Stingelin, N., Drew, A. J., Kreouzis, T. \& Gillin, W. P. Effect of excited states and applied magnetic fields on the measured hole mobility in an organic semiconductor. Phys. Rev. B 82, 085205 (2010).

47. Caruntu, D., Caruntu, G. \& O'Connor, C. J. Magnetic properties of variable-sized $\mathrm{Fe}_{3} \mathrm{O}_{4}$ nanoparticles synthesized from non-aqueous homogeneous solutions of polyols. J. Phys. D Appl. Phys. 40, 5801-5809 (2007).

48. Goya, G. F. et al. Magnetic hyperthermia with $\mathrm{Fe}_{3} \mathrm{O}_{4}$ nanoparticles: the influence of particle size on energy absorption. IEEE Trans. Magn. 44, 4444-4447 (2008).

49. lida, H., Takayanagi, K., Nakanishi, T. \& Osaka, T. Synthesis of $\mathrm{Fe}_{3} \mathrm{O}_{4}$ nanoparticles with various sizes and magnetic properties by controlled hydrolysis. J. Colloid Interface Sci. 314, 274-280 (2007). 